\title{
Methods to Prevent Rumors Spread on Micro-blog in China - A Case Study Based on the Analysis of Ten Typical Rumors Spread on Sina Micro-blog from 2017 to 2018
}

\author{
Xinmeng Qin \\ School of Management, Capital Normal University, Beijing, China
}

Keywords: micro-blog rumor; management; case analysis

\begin{abstract}
Internet rumors bring endless troubles to the government on social governance. The emergence of "micro-blog" facilitates the spread of rumors. By analyzing typical rumors spread on micro-blog from February, 2017 to February, 2018, this paper sums up difficulties in the practice of dispelling rumors, and puts forward a set of methods which can refute rumors from three aspects, cultivating the rumor awareness of netizens, establishing an emergency disposal system for preventing and controlling key rumors, and coordinating public powers.
\end{abstract}

\section{Introduction}

In the Internet era, information can quickly spread among people with different identities and from different regions; we are now facing a more complicated public opinion environment. Among public opinion fields on the network, micro-blog has become the most powerful one through its completely open and relatively free atmosphere. According to official statistic data released by Sina, the number of users of micro-blog has reached 392 million by the end of 2017. Such a large number of Internet users bring great difficulties to the supervision of network information.

In recent years, our government has been making efforts in micro-blog rumor control. In terms of information disclosure, government agencies and departments have registered official micro-blog accounts to interact with people. The most typical example is the micro-blog accounts set by local public security organizations. Micro-blog accounts greatly help public security organizations to collect information, gather public opinions, disclose case investigation progress, and deal with public crisis. Since then, micro-blogs about government affairs has been increasing. By the end of 2017, certified government micro-blog accounts reached 173569, with 80.92 million micro-blogs about government affairs. 1 When dealing with emergencies, the government use these micro-blog accounts to release first hand information, refute the rumor, guide public opinions and pacify people's emotions. In terms of legal regulation, on February 2, 2018, the national Internet Information Office issued the Regulation on the Management of Micro-blog Information Service. It clearly stipulates that micro blog information providers should take the responsibility of information management (the sixth article); a sound rumor refuting mechanism should be established (the eleventh article) to prevent and control rumors. The introduction of this regulation marks the implementation of self-regulation and cooperative rumor control measures.

Although the government has formulated a series of measures to deal with rumors, on micro-blog, rumors still exist. Sensational rumors occasionally occur and arouse hot discussion. The legal regulation and administrative disposal measures should be continuously improved.

\section{Data Collection}

This paper collects 10 hottest rumours with the highest search volume on micro-blog from February 2017 to February 2018, and sums up the time and process of rumour spread, as well as their contents, characteristics, refuting methods and social influences. Specific contents can be seen in Table 1. 
Table 1 Ten micro-blog rumors spread from 2017 to 20182

\begin{tabular}{|c|c|c|c|}
\hline Rumor & Case & How to refute the rumor & Social impacts \\
\hline $\begin{array}{c}\text { Plastic } \\
\text { Porphyra }\end{array}$ & $\begin{array}{l}\text { In February 2017, Wang doubted that the Porphyra he } \\
\text { purchased was made of plastic. He recorded a video } \\
\text { with his friends and uploaded the video to prevent } \\
\text { people from eating Porphyra. Then he used this video } \\
\text { to extort Porphyra enterprises. }\end{array}$ & $\begin{array}{l}\text { Government refute the } \\
\text { rumor through official } \\
\text { micro-blog account } \\
\text { + NGO refute the rumor + } \\
\text { media refute the rumor }\end{array}$ & $\begin{array}{l}\text { serious } \\
\text { (economic loss }+ \\
\text { reputational } \\
\text { loss) }\end{array}$ \\
\hline $\begin{array}{l}\text { The death of } \\
\text { a Tai Fu } \\
\text { Middle } \\
\text { School } \\
\text { student }\end{array}$ & $\begin{array}{l}\text { In April 1, 2017, a corpse was found in Tai Fu Middle } \\
\text { School, Luxian County, Sichuan. Some people said the } \\
\text { victim was beaten to death by } 5 \text { school bullies, } \\
\text { including the son of the principal, the son of the police } \\
\text { inspector and the son of the mayor; the school and the } \\
\text { police wanted to close the case as suicide, but more } \\
\text { than } 200 \text { of the victim's family members snatched the } \\
\text { corpse at the funeral parlor; the police controlled these } \\
\text { relatives. }\end{array}$ & $\begin{array}{l}\text { the government hold } \\
\text { press conference }+ \text { use } \\
\text { official micro-blog } \\
\text { account to refute the } \\
\text { rumor }\end{array}$ & 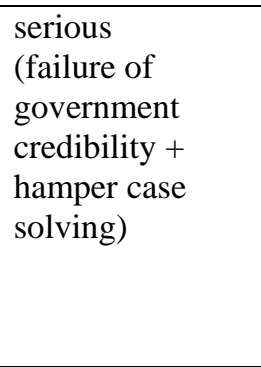 \\
\hline $\begin{array}{l}\text { Xiong'an } \\
\text { New } \\
\text { District }\end{array}$ & $\begin{array}{l}\text { In April 1, 2017, the CPC Central Committee and the } \\
\text { State Council decided to set up a state-level new } \\
\text { district in Xiong'an. } 87 \text { central enterprises would move } \\
\text { to Xiong'an; license-plate lottery began to take effects } \\
\text { in Baoding from June; compensation agreement would } \\
\text { be issued in May; the third airport of the capital would } \\
\text { be located at Xushui District of Baoding; Tsinghua } \\
\text { University would move to Xiong'an. }\end{array}$ & $\begin{array}{l}\text { The government refute } \\
\text { the rumor through official } \\
\text { micro-blog account }+ \\
\text { WeChat account }\end{array}$ & $\begin{array}{l}\text { Medium } \\
\text { (policy } \\
\text { misreading) }\end{array}$ \\
\hline $\begin{array}{l}\text { Hawking } \\
\text { warned } \\
\text { moon } \\
\text { landing }\end{array}$ & $\begin{array}{l}\text { June } 19,2017 \text {, an account named BBC global } \\
\text { information search issued a micro-blog: Hawking } \\
\text { warned again not to go to the moon; aliens lived on the } \\
\text { back of the moon. }\end{array}$ & $\begin{array}{l}\text { The public refute the } \\
\text { rumor spontaneously }\end{array}$ & mild \\
\hline $\begin{array}{l}\text { Wu Jing's } \\
\text { family } \\
\text { members } \\
\text { are all } \\
\text { foreigners }\end{array}$ & $\begin{array}{l}\text { August 2017, a micro-blog user expressed that Jing } \\
\text { Wu, the star of a hot film Wolf Warriors } 2 \text { was not } \\
\text { Chinese nationally, neither were his family members. } \\
\text { "The person who abandoned China educate you to be } \\
\text { patriotic." }\end{array}$ & $\begin{array}{l}\text { Person involved use } \\
\text { micro-blog to refute the } \\
\text { rumor }\end{array}$ & $\begin{array}{l}\text { Medium } \\
\text { (impaired } \\
\text { personal } \\
\text { reputation) }\end{array}$ \\
\hline $\begin{array}{l}\text { return } \\
\text { earthquake } \\
\text { donation }\end{array}$ & $\begin{array}{l}\text { After the earthquake in Jiuzhaigou Valley, August } \\
2017 \text {, some citizens received a message from the } \\
\text { rescue center of the Seismological Bureau, appealing } \\
\text { for donations and promising that the donation would be } \\
\text { returned by two times after the disaster. }\end{array}$ & $\begin{array}{l}\text { The official micro-blog of } \\
\text { the Seismological Bureau } \\
\text { refute the rumor }\end{array}$ & mild \\
\hline $\begin{array}{l}\text { The death of } \\
\text { Shi-jian Chu }\end{array}$ & $\begin{array}{l}\text { September 13, 2017, Wei Wang, the director general of } \\
\text { Chinese Museum of Finance, posted a micro-blog, } \\
\text { saying that Shi-jian Chu, the most inspiring senior } \\
\text { entrepreneur, had died. The rumor spread rapidly on } \\
\text { the Internet. }\end{array}$ & $\begin{array}{l}\text { Personal micro-blog }+ \\
\text { WeChat }+ \text { media refute } \\
\text { the rumor }\end{array}$ & $\begin{array}{l}\text { medium } \\
\text { (personal life } \\
\text { interference) }\end{array}$ \\
\hline $\begin{array}{l}\text { Micro- } \\
\text { blog visitor } \\
\text { checking }\end{array}$ & $\begin{array}{l}\text { In September 2017, a number of micro-blog service } \\
\text { accounts said that by spending } 3 \text { to } 20 \text { yuan, users } \\
\text { could check who had recently browsed their accounts. }\end{array}$ & $\begin{array}{l}\text { Sina micro-blog refute the } \\
\text { rumor }\end{array}$ & mild \\
\hline $\begin{array}{l}\text { Military } \\
\text { personnel } \\
\text { indecency } \\
\text { with } \\
\text { children }\end{array}$ & $\begin{array}{l}\text { November 2017, after the child abuse was exposed in } \\
\text { Red, Yellow and Blue Kindergarten, some accounts } \\
\text { issued "the director of the kindergarten collude with } \\
\text { her husband and force children to be obscened". The } \\
\text { massage was quickly forwarded by the accounts of } \\
\text { some media and celebrities, causing serious social } \\
\text { impacts. }\end{array}$ & $\begin{array}{l}\text { Related units and police } \\
\text { refute the rumor through } \\
\text { micro-blog }+ \text { the celebrity } \\
\text { apologize and forward the } \\
\text { micro-blog }\end{array}$ & $\begin{array}{l}\text { serious } \\
\text { (the reputation } \\
\text { of military is } \\
\text { damaged + cause } \\
\text { social panic) }\end{array}$ \\
\hline $\begin{array}{l}\text { A little boy } \\
\text { rabies } \\
\text { attacks }\end{array}$ & $\begin{array}{l}\text { In late February 2018, the video about a rabid attack } \\
\text { boy who kept barking and was firmly controlled by } \\
\text { three people spread on the Internet. The boy came from } \\
\text { Yingde, Guangdong Province. }\end{array}$ & $\begin{array}{l}\text { Public security organs } \\
\text { and epidemic prevention } \\
\text { departments refute the } \\
\text { rumor through } \\
\text { micro-blog. }\end{array}$ & $\begin{array}{l}\text { serious } \\
\text { (personal mental } \\
\text { injury + cause } \\
\text { social panic) }\end{array}$ \\
\hline
\end{tabular}




\section{Case Analysis}

According to the contents of rumours, these rumors can are divided into five categories: social hot spots (The death of Tai Fu middle school student, returning earthquake donation, military personnel indecency with children), food hygiene (plastic Porphyra, rabies attack), celebrity and news (the nationality of Jing Wu, The death of Shi-jian Chu), public policy (Xiong'an New District), Internet, science and technology (Micro- blog visitor checking, Hawking warned moon landing).

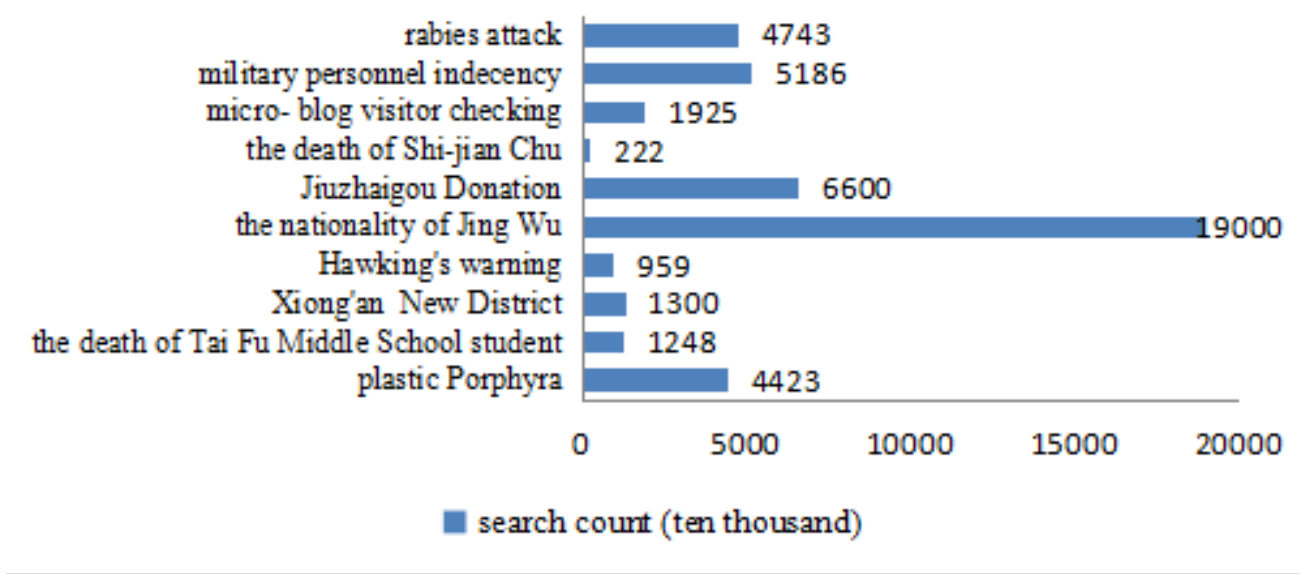

Figure 1 The search volume of ten rumours on the Internet

(data source: People’s Daily Online)

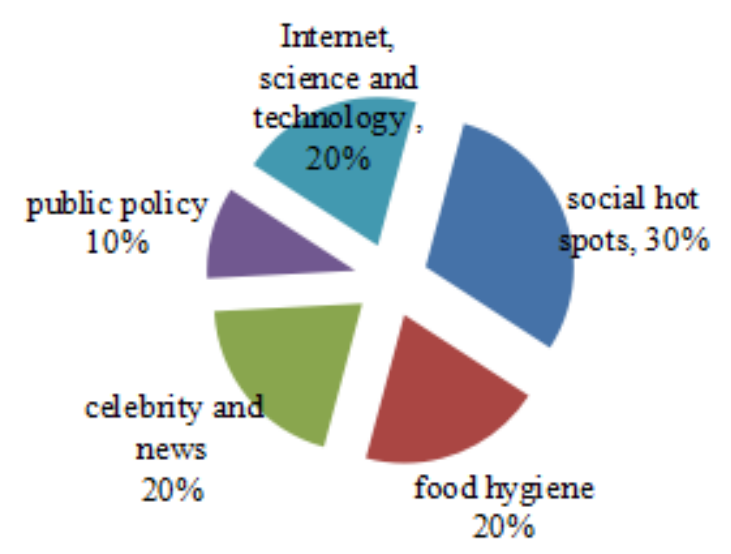

Figure 2 The proportions of different kinds of rumors

According to Figures 1 and Table 1, the rumor about the nationality of Jing Wu has the highest search volume. Celebrity rumors have the characteristic of rapid dissemination; their popularity depend on the reputation of celebrities. Their influence on individual is greater than that of society. Generally speaking, these rumors are refuted by individuals.

According to Figure 2 and Table 1, rumors about social hot spots, like the death of a Tai Fu Middle School student and military personnel indecency with children, are most common, and have great negative impacts on the society. People who cook up these stories often have the tendency of slandering national units. Compared with other rumors, these rumors can easily cause anger feelings, which can make citizens buy the story blindly and further spread the rumors. This kind of rumor should be refuted by state agencies through disclosing the progress of investigating the contents of rumors. Media, non-governmental organizations and individuals need to rely on official channels and forward rumor refuting micro blogs. After refuting the rumor, the person who starts the rumor would be arrested for violating the criminal law or the law of public security.

In addition to social hot spots, rumors on food and healthy can easily cause public panic and have negative impacts on the society in a certain period of time. But after refuting the rumor, the social 
influences of these rumors are drastically reduced. In such incidents, non-governmental organizations, media, reporters and citizens choose to verify the rumors spontaneously, which greatly reduce the pressure of authorities.

Rumors on science and technology do not have great social impacts since few people tend to believe them. Researchers in related fields take the initiative to refute rumors.

\section{Conclusion}

Based on above analysis, this paper concludes that in the practice of controlling micro-blog rumors, following difficulties exist.

First, from the perspective of rumor monitoring, technically, the micro-blog platform is lack of rumor detection and information audit mechanism. In laws and regulations, the public are lack of legal awareness. The purpose of plastic Porphyra rumor is to retaliate Porphyra enterprises, but it ends in crimes of rumor spreading and extortion.

Secondly, in the process of public opinion guidance, not all officials can guide public opinions effectively; the degree of information openness is influenced by the progress of case investigation. Thus, the truth cannot be deeply rooted in the hearts of people. The public are wandering on the border of rumor and truth, and even tend to believe the rumor. Media also serve a channel of guiding public opinion, but the large number of media makes the industry difficult to control, let alone self-discipline. Some low quality media accounts because even become the source of rumors. In addition, news is the most competitive resource of media. Investigation the authenticity of the news will cost time and energy, which conflicts with the industry goals to a certain extent.

Moreover, people have different degrees of immunity to different types of rumors. Simply appealing to the masses to build anti-rumor awareness cannot solve the problem. The plight of anti-rumor education is, when people are frightened or irritated by the rumor, they cannot think deeply and use their reasoning ability. They are threatened by the rumors. For instance, in the case of the death of a Tai Fu Middle School student, some citizens were inconsistent with the practice of government agencies, and even opposed to governments' administration.

On the whole, in the practice of rumor control, there is no complete set of governance system which can coordinate resources. First, relevant government departments do not have an emergency plan to respond to rumors. In most cases, when the authority chooses to control a rumor, the rumor has been spread in large scale and become the hot spot event itself. At that time, the government does not have corresponding solutions; the truth is less persuasive than the rumor. Secondly, government staff cannot clearly tell which rumors can exert great social influences. They cannot coordinate with folk organizations, or use monitoring technology and public opinion guidance measures effectively to avoid the attack of rumors.

\section{Summary and Suggestions}

Through case analysis, this paper holds that the primary task of rumor management is to establish a rumor governance system by relevant departments. Different kinds of rumors have different dissemination channels, scopes and influences. Micro-blog is a open media platform; everyone can become the self-media information disseminators. Micro blog users have different qualities; their ability of telling rumors is far worse than that of the mainstream media. In addition, micro-blog sets up a network platform for information communication between strangers. On that platform, users can disseminate information quickly; there are few limits on the contents of information. Thus, multiples rumors harmful to public security can be spread on micro-blog. Moreover, micro-blog has a large number of accounts of mainstream media, celebrities, as well as other influential organizations and characters. The micro-blog posted or forwarded by these accounts have great social impacts. Therefore, the micro-blog rumor control system should include following three parts.

Cultivating Internet users' rumor awareness. Internet users' rumor awareness is the foundation of controlling rumor spreading. Many researchers believe that netizens should be self-disciplined and actively improve their media literacy; they should not start rumors, believe rumors or spread rumors.3 
But from the perspective of regulation, netizens' self-discipline is not a part of governance. Raising netizens' rumor awareness means to prevent them from starting rumors, believing rumors and spreading rumors. The key of guiding of popular opinion lies in the public opinion guidance ability of government agencies and influential mainstream media. Therefore, it is necessary to cultivate the public opinion control abilities of government staff and the communication abilities of media personnel, in order to effectively guide the public to get out of the trap of rumor, and improve their abilities to resist similar rumors.

Emergency disposal mechanism. In recent years, rumors about public events frequently occur. The disposal of rumors should also be included in contingency plans. For rumors will have great influence, the government should set up an emergency management agenda and contingency plans to prevent and control key rumors ahead of time. The plan should include following aspects: key rumor detection mechanism, information release mechanism before and after the rumor appears, the monitoring of rumor, the control and guidance of public opinion, and the summary after rumor spreading.

Coordinating public powers. From the angle of subject composing, scholar Rong Liu believes that the government is the leader of governance; the public is the foundation of governance; NGOs are the link of governance. 4 The government plays an important role in eliminating the "information deficit"; in-depth reports and rumor analysis released by media or individuals can make relevant information more transparent. 5 But at present, the forces of all parties are too dispersed and cannot be coordinated. Therefore, we should register special rumor refuting organizations and establish good communication relationship with folk forces. After the rumor appears, it is necessary to communicate with them and get the evidence of rumor in time. A reward and punishment mechanism for public opinion leaders' participation in rumor management should also be established, in order to reward celebrities who the initiative to refute rumors, and punish who spread rumors more widely.

\section{Acknowledgement}

This work is supported by the science foundation of Beijing Municipal Education Commission (NO.KM200810028021, NO. KM201610028019).

\section{References}

[1] Public Opinion Monitoring Committee, People’s Daily Online, 2017 Government Administration Index: Report on the Power of Micro-blog, R. People’s Daily Online, Micro-blog, Sina. com, Beijing, 2018

[2] People’s Daily Online, 2017 Rumor Memorandum [EB/OL].

Http://society.people.com.cn/n1/2018/0130/c229589-29795192.html

[3] J. Ang, X. Yu, Research on the spread of Internet rumor and management countermeasures: take the previous two Monthly Report on Micro-blog Rumor Refuting as an example, J. Journal of the Shandong Agriculture Engineering University.33 (2016).

[4] R. Liu, Y. Liu, The multi-subject structure of Internet rumor control in the context of good governance, J. Social Sciences in Guangxi. 09 (2012).

[5] X. Yang, Local government should reflect on the current situation and existing problems of Internet rumors: a study based on typical cases of "refuting Internet rumors”, J. Journal of Chongqing University (Social Science Edition). 22 (2016). 